Portland State University

PDXScholar

$1-10-1984$

\title{
The Effect of Viscosity on Impact Cratering and Possible Application to the Icy Satellites of Saturn and Jupiter
}

Jonathan H. Fink

Portland State University, jon.fink@pdx.edu

Donald Gault

Arizona State University

Ronald Greeley

Arizona State University

Follow this and additional works at: https://pdxscholar.library.pdx.edu/geology_fac

Part of the Geology Commons, and the Instrumentation Commons

Let us know how access to this document benefits you.

\section{Citation Details}

Fink, J., Gault, D., \& Greeley, R. (1984). The Effect of Viscosity on Impact Cratering and Possible Application to the Icy Satellites of Saturn and Jupiter. Journal of Geophysical Research: Solid Earth (1978-2012), 89(B1), 417-423.

This Article is brought to you for free and open access. It has been accepted for inclusion in Geology Faculty Publications and Presentations by an authorized administrator of PDXScholar. Please contact us if we can make this document more accessible: pdxscholar@pdx.edu. 


\title{
The Effect of Viscosity on Impact Cratering and Possible Appliçation to the Icy Satellites of Saturn and Jupiter
}

\author{
JONATHAN FINK \\ Department of Geology, Arizona State University \\ DONALD GAULT \\ Murphys Center for Planetology \\ RONALD GREELEY \\ Department of Geology, Arizona State University
}

\begin{abstract}
Impact experiments in Newtonian fluids with a range of viscosities of $10^{-3}$ to $60 \mathrm{~Pa}$ s demonstrate that transient crater volume and shape (depth-to-diameter ratio) depend on target viscosity as well as on gravity. Volume is reduced, and depth-to-diameter ratio is increased for cratering events in which viscosity plays a dominant role. In addition to being affected by target kinematic viscosity, viscous scaling is most strongly - influenced by projectile diameter, less strongly by projectile vêlocity, and least strongly by gravity. In a planetary context, viscous effects can occur for craters formed by small or slow moving impacting bodies, low planetary surface densities, high surface viscosities, and low gravity values; conditions all likely for certain impacts into the icy satellites of Saturn and Jupiter, especially if liquid mantles were still present beneath solid crusts. Age dating based on crater counts and size-frequency distributions for these icy bodies may have to be modified to account for the possibility that viscosity-dominated craters were initially smaller and depeper than their gravity-controlled counterparts.
\end{abstract}

\section{INTRODUCTION}

Hypervelocity and centrifuge impact experiments have been used to derive scaling laws which can relate the dimensions of planetary craters to impact conditions and crustal properties of various planets [e.g., Gault, 1973; Holsapple and Schmidt, 1982]. These experiments have primarily involved dry target materials which are most appropriate for interpreting impacts into volatile-depleted bodies like the moon and Mercury, where cratering processes are dominated by the effects of gravity, the strength of the crust, and the properties of the impacting body. Impacts into the surfaces of the icy Saturnian and Galilean satellites, and to a lesser extent Mars, may not be fully explained by strength and gravity effects alone. For example, current hypotheses concerning the origin of certain distinctive crater forms on these bodies ascribe their morphologies to the hydrodynamic oscillation of material in their tránsient cavities [e.g., Greeley et al., 1980]. Thus the relatively high crustal volatile contents may modify cratering processes in ways that require scaling laws which take account of the effective viscosity of the planetary crust during impact.

In this paper we present preliminary results from a series of impact experiments conducted at the NASA Ames Vertical Gun Range in which the targets were Newtonian (strengthless) fluids of variable viscosity: These experiments indicate that under certain conditions, target viscosity has a significant effect on crater volume and depth.

\section{Copyright 1984 by the American Geophysical Union.}

Paper number 3B1579.

0148-0227/84/003B-1579\$05.00
These conditions seem especially likely to occur for part of the crater population on the icy satellites of the outer planets and may serve to complicate interpretation of the histories of these satellites based on crater statistics.

\section{EXPERIMENTAL DATA}

All planetary surfaces appear to have heterogeneous material properties, which may be approximated by different, simple rheological models. Experimental impacts into volatile-free targets, analogous to the surfaces of the moon and Mercury, indicate that cohesive strength and the coefficient of internal friction [Schmidt, 1980] are the most important properties controlling final crater form. The presence of crustal volatiles on Mars, in conjunction with atmospheric effects [Schultz and Gault, 1979], is believed to lead to craters with distinctly fluidal ejecta morphology [Carr et al., 1977; Gault and Greeley, 1978]. The potential fluidlike behavior of the Martian crust has been explained by assuming that shock-induced heating melts ground ice, forming a slurry that has a Bingham rheology; that is, the impacted material behaves as a fluid when subjected to high stresses and as a solid under lower stresses. Impacts into Bingham targets may produce hydrodynamic oscillations of material in the transient crater bowl, the number and height of these oscillations being controlled, by the effective viscosity and strength of, the target material [Greeley et'al., 1980; Fink et al., 1981; Melosh, 1982]. Impact into a surface composed of ice and rock like those of the icy satellites of Saturn and Jupiter may also generate a local slurry characterized as a Bingham material [Horner and Greeley, 1982].

In order to explore the scaling relations for impacts into Bingham' materials we have conducted two sets of experi- 
ments. The first series [Gault and Greeley, 1978; Greeley et al., 1980, 1982; Fink et al., 1981] used clay slurry targets and was concerned primarily with crater and ejecta morphology. The strengths and viscosities of clay slurries are not independent properties; rather they both depend on water content. Moreover, determining the precise dimensions of transient craters in opaque materials like clay slurries is not possible. For these reasons the second series of experiments was conducted using clear, strengthless viscous targets.

Impact experiments have been conducted using clear silicone oils of four different viscosities. These data combined with those for water [Gault and Wedekind, 1978; Gault and Sonett, 1982] cover a range of viscosities from $10^{-3}$ to $60 \mathrm{~Pa} \mathrm{~s}(1 \mathrm{~Pa} \mathrm{~s}=10 \mathrm{p})$. Silicone oils were selected because they are transparent, allowing precise measurement of transient crater bowl depths, diameters, and volumes, and because their densities, surface tensions, and thermal properties remain nearly constant over a viscosity range of almost 5 orders of magnitude [Dow Corning Company, 1966]. In addition, their densities and surface tensions are close to those of water.

Target fluids were placed in a clear plastic tank measuring $1 \mathrm{~m}$ on a side to a depth of $20 \mathrm{~cm}$; edge effects were found to be negligible during formation of all the transient crater bowls. Experiments were conducted using pyrex, aluminum, and nylon projectiles with diameters of 0.16 , $0.32,0.48$, and $0.64 \mathrm{~cm}(1 / 16,1 / 8,3 / 16$, and $1 / 4$ inch). Projectile velocities ranged from 0.43 to $6.62 \mathrm{~km} / \mathrm{s}$. Ambient pressure was monitored and kept between 5 and $15 \mathrm{~mm}$ $\mathrm{Hg}\left(1 \mathrm{~mm}=1.33 \times 10^{2} \mathrm{~Pa}\right)$. Temperature was maintained between $22^{\circ}$ and $24^{\circ} \mathrm{C}$. Impacts were recorded on highspeed motion pictures (400 frames/s), and the projected films were then used to determine the volumes, depths, and diameters of the transient crater bowl at the time of maximum crater volume and at the time of maximum crater depth. In this paper we report on a representative subset of 58 experiments which used pyrex projectiles of 0.16 , 0.32 , and $0.48 \mathrm{~cm}$ diameter (Table 1 ).

\section{RESULTS}

The dynamic responses of the different fluids to impact depended upon their viscosities. For water and oils of relatively low viscosity, impact produced an enlarging crater bowl whose floor then rose into a central peak which could oscillate one or more times. For oils of the highest viscosities, the transient crater bowls collapsed slowly without forming a central peak. Conditions necessary for the formation of central peaks are considered in a companion paper (J.H. Fink et al., manuscript in preparation, 1984). In the present study we, were most concerned with the volumes and shapes of the first transient crater bowl, regardless of its later dynamic evolution. Our goal was to find functional relationships among these geometric quantities, the properties of the impacting body, and the rheology of the target material. Dynamic models [e.g., Fink et al., 1981; Melosh, 1982] have already related the number of oscillations to the volume (and potential energy) of the transient crater bowl.

Earlier experimental impacts into water and sand targets showed that crater volume $(V)$ depended on target density $(\rho)$, strength $(Y)$, and internal friction angle $(\phi)$, gravity $(g)$, projectile mass $(m)$, density $(\delta)$, and diameter $\left(D_{p}\right)$, and either projectile momentum $(M)$ [Holsapple and Schmidt, 1982] or energy $(E)$ [Gault and Wedekind, 1977, 19781. Momentum and energy scaling can both be formally included in an analytical model in which the cratering process is divided into two general stages [Holsapple, 1982]. During the first stage; very high stresses are generated, and the particle motion is essentially independent of low pressure (mechanical) properties of the target and of gravity. The projectile density, diameter, and velocity " $(u)$ control the magnitude of the shock stresses generated during this stage. During the second stage, the target response is controlled by its material properties, gravity, and a single coupling parameter, $C$, determined during the initial stage. $C$ takes the form $m u^{\mu}$, or $D_{p} u^{\mu}$, where $\mu$ can range between 1 and 2 in the first case or between $1 / 3$ and $2 / 3$ in the latter case. Using this approach, the number of independent variables affecting any dependent crater dimension is reduced, and momentum and energy scaling are both seen to be special cases with different values of $\mu$.

Our experimental data (Table 1) were initially combined into the same dimensionless groups used in earlier studies [Holsapple and Schmidt, 1980, 1982], with the exclusion of target strength and internal friction angle, which are both zero for these fluids. Dimensionless crater volume $\left(\pi_{1}=V \rho / m\right)$ was plotted against Froude number $\left(\pi_{2}=1.61 \mathrm{~g} D_{p} / u^{2}\right)$, giving separate curves for different target viscosities and projectile masses. Each curve has the form $\pi_{1} \pi_{2} a=k_{1}$, where $k_{1}$ is a constant that increases as the inverse of target viscosity $(\eta)$ (Figure 1). Expanding this expression gives (for fixed $\rho$ and $\delta$ )

$$
V \propto D_{p} 3-a_{u} 2 a_{g}-a
$$

This equation shows that $D_{p}$ and $u$ can be combined into a coupling parameter of the form $C \propto D_{p} u \mu$, where $\mu$ is constrained as

$$
\mu=2 a /(3-a)
$$

To find the additional dependence of crater volume on viscosity, we perform a second dimensional analysis considering the Reynolds number $\left(\pi_{3}=\eta / \rho D_{p} u\right)$, and using $C$ in place of $D_{p}$ and $u$. The six dimensional variables $(V, C, \delta, g, \eta, \rho)$ yield three new dimensionless groups:

$$
\begin{gathered}
\pi_{1}^{*}=V g a /\left(C^{3-a}\right)=\left(V / D_{p}{ }^{3}\right)\left(g D_{p} / u^{2}\right)^{a}=\pi_{1} \pi_{2} a \\
\pi_{2}^{*}=\eta /\left[\rho C(3-a) / 2_{g}(1-a) / 2\right]=\left(\eta / \rho D_{p} u\right)\left(g D_{p} / u^{2}\right)(a-1) / 2 \\
=\pi_{3} \pi_{2}(a-1) / 2 \\
\pi_{3}^{*}=\rho / \delta
\end{gathered}
$$

Preliminary investigation indicated that $\pi_{1}$ * is independent of $\pi_{3}{ }^{*}$, leaving the single dimensionless equation:

$$
\pi_{1}^{*}=F\left(\pi_{2}^{*}\right)
$$

or $\pi_{1} \pi_{2} a=F\left[\pi_{3} \pi_{2}(a-1) / 2\right]$, where $F$ is a function to be determined. 
TABLE 1. Experimental Data for Impacts Into Viscous Media

\begin{tabular}{|c|c|c|c|c|c|c|c|c|c|c|c|c|c|c|c|}
\hline Shot \# & $\begin{array}{c}\eta \\
\mathrm{g} / \mathrm{cm}, \mathrm{s}\end{array}$ & $\stackrel{\rho}{\rho}$ & $\begin{array}{l}D_{p} \\
\mathrm{~cm}\end{array}$ & $\begin{array}{c}m \\
\times 10^{-3} \mathrm{~g}\end{array}$ & $\begin{array}{c}u, \\
\times 10^{5} \mathrm{~cm} / \mathrm{s}\end{array}$ & $\begin{array}{c}V \\
\mathrm{~cm}^{3}\end{array}$ & $\begin{array}{l}d_{c} \\
\mathrm{~cm}\end{array}$ & $\begin{array}{l}D_{c} \\
\mathrm{~cm}\end{array}$ & $\begin{array}{l}\pi_{1} \\
\frac{V_{\rho}}{m}\end{array}$ & $\begin{array}{c}\begin{array}{c}\pi_{2} \\
1.61 g D_{p}\end{array} \\
u^{2}\end{array}$ & $\begin{array}{c}\pi_{3} \\
\frac{\eta}{\rho D p^{u}}\end{array}$ & $\begin{array}{c}\pi_{1}^{*} \\
\pi_{3} \pi_{2}^{0.6}\end{array}$ & $\begin{array}{c}\pi_{2}^{*} \\
\pi_{3} \dot{\pi}_{2}^{-0.2}\end{array}$ & $\begin{array}{c}\pi_{3}^{*} \\
\frac{\rho}{\delta}\end{array}$ & $\begin{array}{l}\pi_{4}^{*} \\
d_{c} \\
D_{c}^{-}\end{array}$ \\
\hline 1 & $1.00 \mathrm{E}-2$ & 1.00 & 0.159 & 4.8 & 2.26 & $2.25 \mathrm{E} 3$ & 10.1 & 20.9 & $4.69 \mathrm{E} 5$ & $4.91 \mathrm{E}-9$ & $2.78 \mathrm{E}-7$ & 4.85 & $1.28 \mathrm{E}-5$ & 0.439 & 0.48 \\
\hline 2 & $1.00 \mathrm{E}-2$ & $1: 00$ & 0.159 & 4.8 & 2.12 & $2.27 \mathrm{E} 3$ & 10.3 & 20.9 & $4.73 \mathrm{E} 5$ & $5.58 \mathrm{E}-9$ & $2.97 \mathrm{E}-7$ & 5.28 & $1.33 \mathrm{E}-5$ & 0.439 & 0.49 \\
\hline 3 & $1.00 \mathrm{E}-2$ & 1.00 & 0.159 & 4.8 & 1.73 & $1.80 \mathrm{E} 3$ & 8.9 & 19.7 & $3.75 \mathrm{E} 5$ & $8.39 \mathrm{E}-9$ & $3.64 \mathrm{E}-7$ & 5.35 & $1.50 \mathrm{E}-5$ & 0.439 & 0.45 \\
\hline 4 & $1.00 \mathrm{E}-2$ & 1.00 & 0.159 & 4.8 & 2.73 & $3.02 \mathrm{E} 3$ & 11.1 & 22.9 & $6.29 \mathrm{E} 5$ & $3.36 \mathrm{E}-9$ & $2.30 \mathrm{E}-7$ & 5.18 & $1.14 \mathrm{E}-5$ & 0.439 & 0.48 \\
\hline 5 & $1.00 \mathrm{E}-2$ & 1.00 & 0.159 & 4.8 & 1.47 & $1.40 \mathrm{E} 3$ & 8.4 & 17.3 & $2.92 \mathrm{E} 5$ & $1.16 \mathrm{E}-8$ & $4.28 \mathrm{E}-7$ & 5.06 & $1.65 \mathrm{E}-5$ & .0 .439 & 0.48 \\
\hline 6 & $1.00 \mathrm{E}-2$ & 1.00 & 0.159 & 4.8 & $4.00 \#$ & $3.57 \mathrm{E} 3$ & 11.5 & 25.4 & $7.44 \mathrm{E} 5$ & $1.57 \mathrm{E}-9 \#$ & $1.57 \mathrm{E}-7 \#$ & $3.88 \#$ & $9.05 \mathrm{E}-6 \#$ & 0.439 & 0.45 \\
\hline 7 & $1.00 \mathrm{E}-2$ & 1.00 & 0.159 & 4.8 & $6.00 \#$ & $4.63 \mathrm{E} 3$ & 12.8 & 27.1 & $9.65 \mathrm{E} 5$ & $6.97 \mathrm{E}-10 \#$ & $1.05 \mathrm{E}-7 \#$ & $3.09 \#$ & $7.12 \mathrm{E}-6 \#$ & 0.439 & 0.46 \\
\hline 8 & $1.00 \mathrm{E}-2$ & 1.00 & 0.159 & 4.8 & 2.40 & $2.66 \mathrm{E} 3$ & 10.8 & 22.2 & $5.54 \mathrm{E} 5$ & $4.36 \mathrm{E}-9$ & $2.62 \mathrm{E}-7$ & 5.34 & $1.23 \mathrm{E}-5$ & 0.439 & 0.49 \\
\hline 9 & $1.00 \mathrm{E}-2$ & 1.00 & 0.317 & -39.0 & 2.28 & $1.15 \mathrm{E} 4$ & 17.6 & 36.1 & $2.94 \mathrm{E} 5$ & $9.62 \mathrm{E}-9$ & $1.38 \mathrm{E}-7$ & 4.55 & $5.54 \mathrm{E}-6$ & 0.427 & 0.49 \\
\hline 10 & $1.00 \mathrm{E}-2$ & 1.00 & 0.317 & 39.0 & 1.25 & 5:99E3 & 13.5 & 29.5 & $1.54 \mathrm{E} 5$ & $3.20 \mathrm{E}-8$ & $2.52 \mathrm{E}-7$ & 4.90 & $7.95 \mathrm{E}-6$ & 0.427 & 0.46 \\
\hline 11 & $1.00 \mathrm{E}-2$ & 1.00 & $0: 317$ & 39.0 & 1.68 & $8.87 \mathrm{E} 3$ & 14.9 & 32.9 & $2.27 \mathrm{E} 5$ & $1.77 \mathrm{E}-8$ & $1.88 \mathrm{E}-7$ & 5.07 & $6.68 \mathrm{E}-6$ & 0.427 & 0.45 \\
\hline 12 & $1.00 \mathrm{E}-2$ & 1.00 & 0.317 & 39.0 & 2.52 & $1.31 \mathrm{E} 4$ & 17.7 & 39.0 & $3.36 \mathrm{E} 5$ & $7.88 \mathrm{E}-9$ & $1.25 \mathrm{E}-7$ & 4.62 & $5.22 \mathrm{E}-6$ & 0.427 & 0.45 \\
\hline 13 & 2.00 & 0.97 & 0.159 & 4.7 & 0.79 & $6.20 \mathrm{E} 2$ & 6.8 & 13.6 & $1.28 \mathrm{ES}$ & $4.07 \mathrm{E}-8$ & $1.64 \mathrm{E}-4$ & 4.71 & $4.93 \mathrm{E}-3$ & 0.435 & 0.50 \\
\hline 14 & 2.00 & 0.97 & 0.159 & 4.7 & 0.96 & $8.70 \mathrm{E} 2$ & 7.6 & 15.2 & $1.80 \mathrm{E} 5$ & $2.71 \mathrm{E}-8$ & $1.35 \mathrm{E}-4$ & 5.19 & 4.40E-3 & 0.435 & 0.50 \\
\hline 15 & 2.00 & 0.97 & 0.159 & 4.7 & 1.37 & $1.21 \mathrm{E} 3$ & 8.3 & 16.6 & $2.50 \mathrm{E} 5$ & $1.34 \mathrm{E}-8$ & $9.47 \mathrm{E}-5$ & 4.72 & $3.56 \mathrm{E}-3$ & 0.435 & 0.50 \\
\hline 16 & 2.00 & $0: 97$ & 0.159 & 4.7 & 1.55 & $1.43 \mathrm{E} 3$ & 8.5 & 17.9 & $2.95 \mathrm{E} 5$ & $1.05 \mathrm{E}-8$ & $8.37 \mathrm{E}-5$ & 4.81 & $3.30 \mathrm{E}-3$ & 0.435 & 0.48 \\
\hline 17 & 2.00 & 0.97 & 0.159 & 4.7 & 2.01 & $2.06 \mathrm{E} 3$ & 9.5 & 20.4 & $4.25 \mathrm{E} 5$ & $6.20 \mathrm{E}-9$ & $6.45 \mathrm{E}-5$ & 5.06 & $2.83 \mathrm{E}-3$ & 0.435 & 0.47 \\
\hline 18 & 2.00 & 0.97 & 0.159 & 4.7 & 2.25 & $2.09 \mathrm{E} 3$ & 9.6 & 20.7 & $4.31 \mathrm{E} 5$ & $4.95 \mathrm{E}-9$ & $5.76 \mathrm{E}-5$ & 4.48 & $2.64 \mathrm{E}-3$ & 0.435 & 0.46 \\
\hline 19 & 2.00 & 0.97 & 0.317 & 43.0 & 0.53 & $3.10 \mathrm{E} 3 \#$ & 11.1 & 21.1 & $6.99 \mathrm{E} 4 \#$ & $1.77 \mathrm{E}-7 \#$ & $1.23 \mathrm{E}-4$ & $6.21 \#$ & $2.76 \mathrm{E}-3 \#$ & 0.376 & 0.50 \\
\hline 20 & 2.00 & 0.97 & 0.317 & 43.0 & 1.01 & $5.40 \mathrm{E} 3$ & 13.1 & 28.1 & $1.22 \mathrm{E} 5$ & $4.90 \mathrm{E}-8$ & $6.44 \mathrm{E}-5$ & 5.02 & $1.87 \mathrm{E}-3$ & 0.376 & 0.47 \\
\hline 21 & 2.00 & 0.97 & 0.317 & 43.0 & 1.38 & $7.24 \mathrm{E} 3$ & 14.5 & 31.4 & $1.65 \mathrm{E} 5$ & $2.62 \mathrm{E}-8$ & $4.71 \mathrm{E}-5$ & 4.66 & $1.55 \mathrm{E}-3$ & 0.376 & 0.46 \\
\hline 22 & 2.00 & 0.97 & 0.317 & 43.0 & 1.63 & $8.80 \mathrm{E} 3$ & 15.4 & 33.2 & $2.00 \mathrm{E} 5$ & $1.88 \mathrm{E}-8$ & $3.99 \mathrm{E}-5$ & 4.63 & $1.40 \mathrm{E}-3$ & 0.376 & 0.46 \\
\hline 23 & 2.00 & 0.97 & 0.3 .17 & 43.0 & 1.83 & $9.13 \mathrm{E} 3$ & 15.6 & 34.2 & $2.08 \mathrm{E} 5$ & $1,49 \mathrm{E}-8$ & $3.55 \mathrm{E}-5$ & 4.19 & $1.30 \mathrm{E}-3$ & 0.376 & 0.46 \\
\hline 24 & 2.00 & 0.97 & 0.317 & 43.0 & 1.94 & $9.95 \mathrm{E} 3$ & 16.0 & 34.7 & $2.27 \mathrm{E} 5$ & $1.33 \mathrm{E}-8$ & $3.35 \mathrm{E}-5$ & 4.27 & $1.26 \mathrm{E}-3$ & 0.376 & 0.46 \\
\hline 25 & 2.00 & 0.97 & 0.317 & 43.0 & 2.07 & $9.90 \mathrm{E} 3$ & 15.8 & 34.8 & $2.26 \mathrm{E} 5$ & $1.17 \mathrm{E}-8$ & $3.14 \mathrm{E}-5$ & 394 & $1.21 \mathrm{E}-3$ & 0.376 & 0.45 \\
\hline 26 & 2.00 & 0.97 & 0.317 & 43,0 & 2.19 & $1.05 \mathrm{E} 4$ & 16.7 & 35.2 & $2.39 \mathrm{E} 5$ & $1.04 \mathrm{E}-8$ & $2.97 \mathrm{E}-5$ & 3.88 & $1.17 \mathrm{E}-3$ & 0.376 & 0.47 \\
\hline 27 & $2.85 \mathrm{E} 1$ & 0.97 & 0.317 & 43.0 & 2.89 & $9.30 \mathrm{E} 3$ & 15.8 & 33.4 & $2.10 \mathrm{E} 5$ & $5.99 \mathrm{E}-9$ & $3.20 \mathrm{E}-4$ & 2.45 & $1.41 \mathrm{E}-2$ & 0.376 & 0.47 \\
\hline 28 & $2.85 \mathrm{E} 1$ & 0.97 & 0.317 & 43.0 & 2.22 & $9.40 \mathrm{E} 3$ & 15.5 & 34.0 & $2.12 \mathrm{E} 5$ & $1.02 \mathrm{E}-8$ & $4.17 \mathrm{E}-4$ & 3.40 & $1.65 \mathrm{E}-2$ & 0.376 & 0.46 \\
\hline 29 & $2.85 \mathrm{E} 1$ & 0.97 & 0.317 & 43.3 & 1.74 & $7.40 \mathrm{E} 3$ & 14.4 & 30.6 & $1.66 \mathrm{ES}$ & $1.65 \mathrm{E}-8$ & $5.32 \mathrm{E}-4$ & 3.55 & $1.92 \mathrm{E}-2$ & 0.373 & 0.47 \\
\hline 30 & $2.85 \mathrm{E} 1$ & 0.97 & 0.317 & 43.3 & 1.48 & $5.70 \mathrm{E} 3$ & 13.6 & 28.0 & $1.28 \mathrm{E} 5$ & $2.28 \mathrm{E}-8$ & $6.25 \mathrm{E}-4$ & 3.33 & $2.11 \mathrm{E}-2$ & 0.373 & 0.49 \\
\hline 31 & $2.85 \mathrm{E} 1$ & 0.97 & 0.317 & 43.0 & 1.22 & $4.90 \mathrm{E} 3$ & 13.2 & 26.2 & $1.11 \mathrm{E} 5$ & $3.36 \mathrm{E}-8$ & $7.58 \mathrm{E}-4$ & 3.64 & $2.37 \mathrm{E}-2$ & 0.376 & 0.50 \\
\hline 32 & $2.85 \mathrm{E} 1$ & 0.97 & 0.317 & 43.0 & 0.71 & $2.25 \mathrm{E} 3$ & 10.8 & 19.8 & $5.08 \mathrm{E} 4$ & $9.91 \mathrm{E}-8$ & $1.30 \mathrm{E}-3$ & 3.19 & $3.27 \mathrm{E}-2$ & 0.376 & 0.55 \\
\hline
\end{tabular}


TABLE 1. (continued)

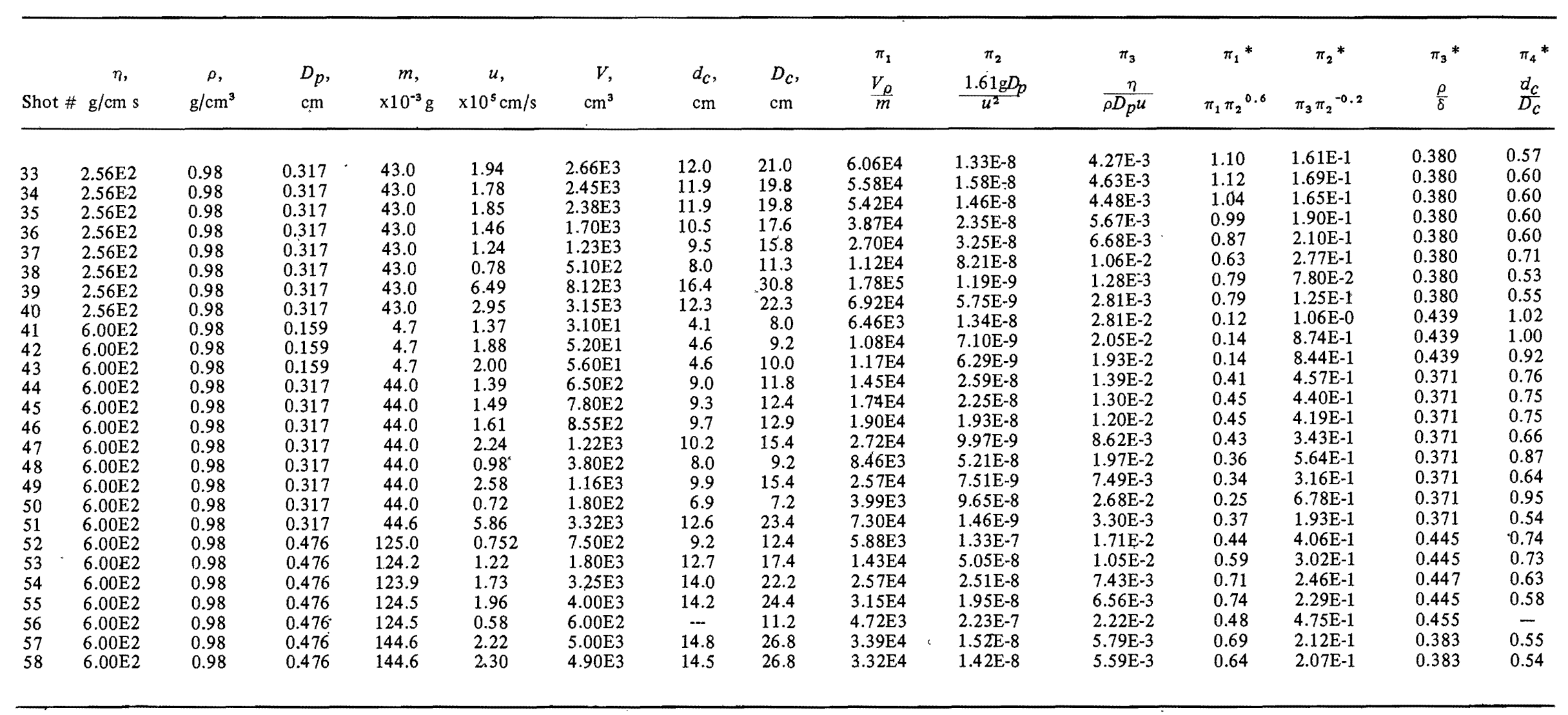




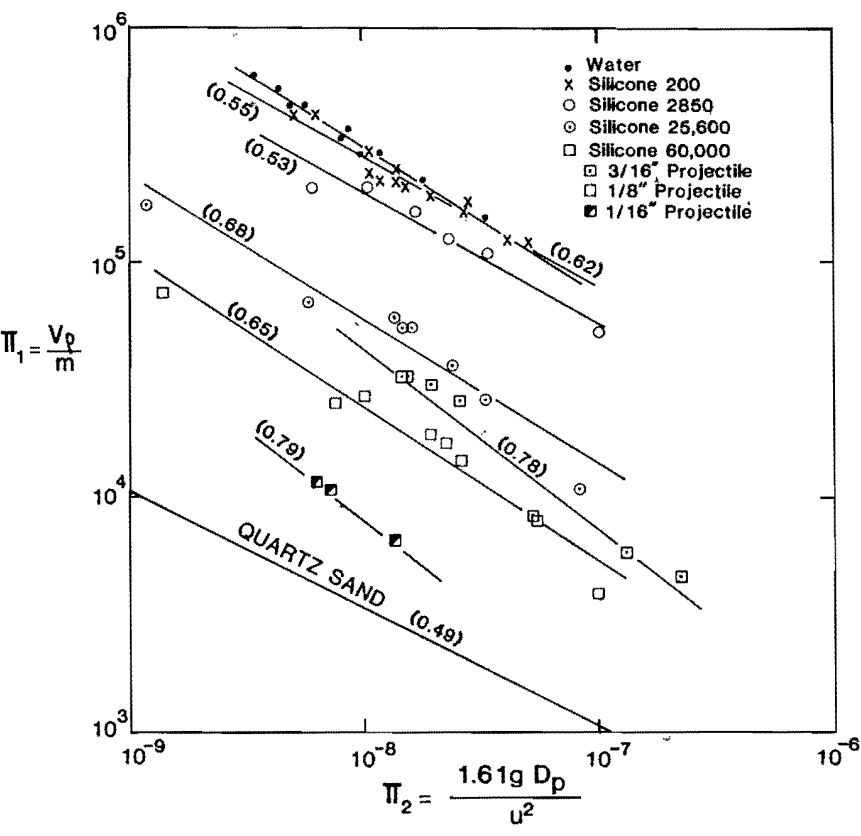

Fig. 1. Log-log plot of cratering efficiency $\left(\pi_{1}\right)$ versus Froude number $\left(\pi_{2}\right)$ for five different fluid media. Plot of quartz sand data [Gault.and Wedekind, 1978] included for comparison. Power law exponents indicated in parentheses.

To find the function $F$, we plotted $\pi_{1} *\left(=\pi_{1} \pi_{2}{ }^{0.6}\right)$ versus $\pi_{2} *\left(=\pi_{3} \pi_{2}{ }^{-0.2}\right.$ ) (Figure 2 ), assuming a value of $a=0.6$. This assumption is based on theoretical arguments [Holsapple and Schmidt, 1982] that $a$ is controlled by porosity and that all liquids should have identical values of about 0.6 . The data plot on a single curve which consists of two parts. For $\pi_{2} *$ values below about 0.005 , the points fall on a horizontal line, indicating no dependence on the Reynolds number, $\pi_{3}$. This represents the so-called gravity scaling regime where $\pi_{1} \pi_{2} a=k_{1}$. For values of $\pi_{2} *$ above $0.005, \pi_{1} *$ decreases, approaching a limiting straight line with a steep negative slope. If we assume that there is a viscous limit above which gravity plays no role, then this limit will be represented by a power law equation, $\pi_{1}^{*} \pi_{2} * B=k_{2}$, (independent of $\pi_{2}$ ). It then follows that

$$
\left(\pi_{1} \pi_{2} a\right)\left[\pi_{3} \pi_{2}(a+1) / 2\right]^{B=\pi_{1}} \pi_{2}^{B}
$$

so that $a+B(a-1) / 2=0$ or $B=2 a /(1-a)$. Thus if we choose $a=0.6, B$ must be 3.0 and the viscous limit will be a straight line with a slope of -3 . It should be emphasized that the existence and form of the coupling parameter, $C$, determines the power law dependence of crater diameter on gravity and viscosity.

Another dimensionless group is required to characterize the shape of the transient crater: the depth-to-diameter ratio $\left(d_{c} / D_{c}\right)$, or $\pi_{4} *$, where the depth and diameter are both measured at the time of maximum depth. A plot of $\pi_{4}^{*}$ versus $\pi_{2} *$ also shows an inflection at a value of $\pi_{2}^{*} \approx 0.005$ (Figure 3 ). Below this value, in the gravity scaling regime, $\pi_{4}^{*}$ has a nearly constant value of about 0.48 . As $\pi_{2} *$ increases toward the viscous regime, the craters progressively deepen. Thus for the same impact conditions, if viscous scaling effects are operating, the crater will be deeper than comparable craters controlled by gravity scaling effects.

In summary, experimental impacts into viscous fluids show that transient crater volume depends upon target viscosity, gravity, and projectile properties. Two distinct regimes can be defined by plotting the dimensionless groups $\pi_{1}^{*}=[V \rho / m]\left[1.61 g D_{p} / u^{2}\right]^{0.6}$ and $\pi_{2}^{*}=$ $\left[\eta / \rho D_{p} u\right]\left[u^{2} / 1.6 g D_{p}\right]^{0.2}$. Below a value of about $\pi_{2}{ }^{*}=$ 0.005 , dimensionless volume is independent of target viscosity, whereas for values of $\pi_{2}^{*}$ larger than about 1.0 , volume decreases steadily as viscosity increases and is independent of gravity. Many of our experimental data points fall in the transition between these two regimes, with $\pi_{2}{ }^{*}$ values between 0.005 and 1.0. Crater depthto-diameter ratios show a similar two-part dependence on viscosity. Below the transition, all craters have approximately the same shape. For larger values of $\pi_{2}{ }^{*}$, craters have progressively smaller diameters for a given depth (or equivalently, craters of the same diameters are deeper). In the next section we consider some of the implications of these results for the interpretation of crater populations on icy bodies, particularly the icy satellites of Saturn.

\section{Planetary APPlications}

Data from impact experiments into viscous fluids (Figures 2 and 3 ) suggest that a transition from gravity to viscous scaling occurs over the range $\pi_{2}^{*}=0.005$ to 1.0 and that the influence of gravity ceases above a value of about $\pi_{2}^{*}=1.0$. Expanding this relation indicates that viscosity should begin to affect cratering when $\eta / \rho D_{p}{ }^{1.2} u^{0.6} g^{0.2}>0.005$. If we assume that these criteria can be extrapolated to planetary scale craters, then viscous effects will be favored by small impactors traveling at low velocities hitting. bodies with low gravitational accelerations and high viscosities. Here we are considering the effective viscosity of the rock/water/ice slurry generated during impact and not the long term, creep-related viscous response of the planetary crust.

Several conditions on the icy Saturnian satellites tend to favor the viscous cratering regime. Two populations of impact craters have been postulated for these icy bodies [Smith et al., 1981; Strom and Woronow, 1982]. The younger group has been attributed to collisions with relatively small, co-orbiting objects from within the Saturnian system. This debris will strike the surface of a satellite at lower velocities than material arriving from elsewhere in the solar system. The icy satellites all have relatively low surface densities and gravitational accelerations. Thus, four of the above criteria for viscous scaling apply.

Viscous scaling is also favored in targets having relatively high viscosities. This viscosity criterion can be evaluated by comparing impact-generated slurries on an icy satellite with terrestrial debris flows. If we consider a $10-\mathrm{km}$ diameter body striking the surface of Enceladus $(g=5.51$ $\mathrm{g} / \mathrm{cm}^{2}$ ) with a velocity of $5 \mathrm{~km} / \mathrm{s}$, viscous scaling effects will begin for target viscosities of about $10^{7} \mathrm{~Pa} \mathrm{~s}$ and will dominate for viscosities greater than about $10^{\circ} \mathrm{Pa}$. Terrestrial debris flows consisting of water, rock, and soil have measured viscosities of up to $10^{4} \mathrm{~Pa} \mathrm{~s}$ [Pierson, 1980]. Adding a significant fraction of ice to an impactgenerated slurry might raise the bulk viscosity the several 


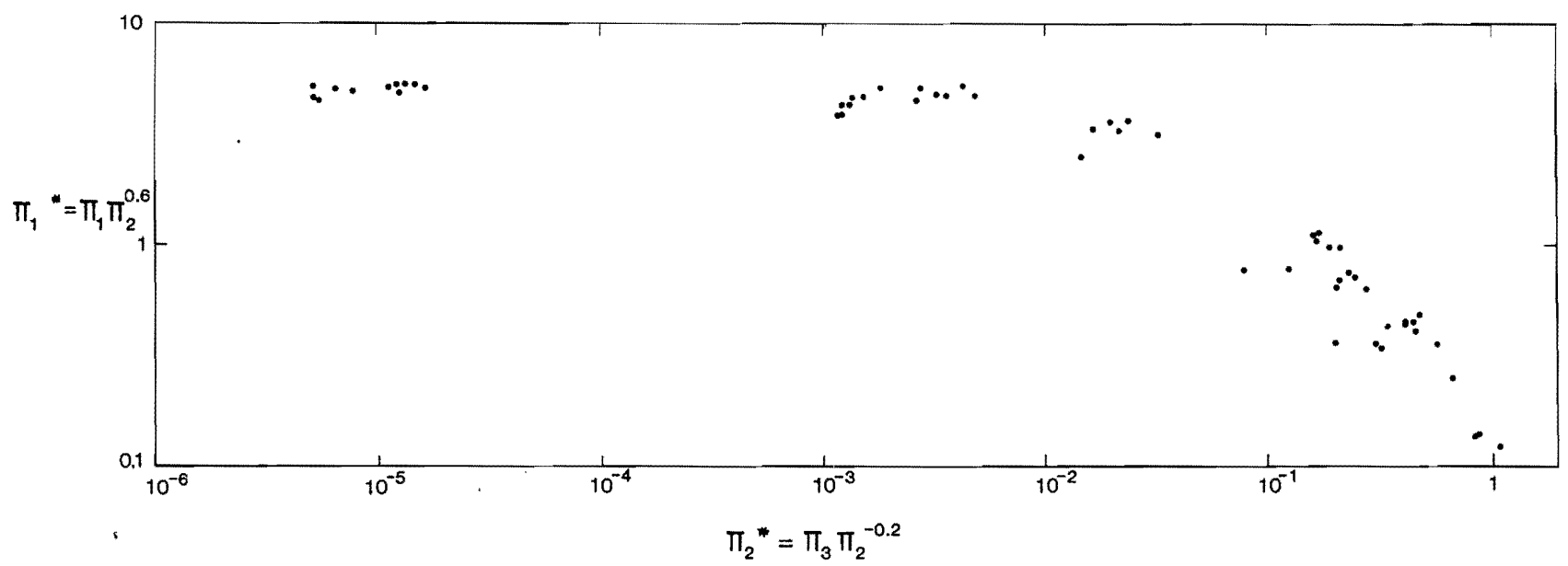

Fig. 2. Log-log plot of crater volume group $\left(\pi_{1}^{*}\right)$ versus viscosity-gravity group $\left(\pi_{2}^{*}\right)$ for data in Table 1 .

orders of magnitude necessary for viscous scaling to apply. The transition from gravity to viscous scaling would occur at lower viscosities for satellites with smaller values of $g$ and for smaller, slower impactors. However, strength effects would also play a significant role in any of these impacts into icy targets of relatively high viscosity.

The relative ages of craters on icy satellites have been estimated from their depth-to-diameter ratios [e.g., Passey and Shoemaker, 1982]. These interpretations assume that all craters form with bowl-shaped profiles and then relax by slow viscous flow over geologic time. Flatter craters are thus assigned greater ages than deeper craters. However, transient craters in relatively fluid crustal materials could have greater depth-to-diameter ratios than craters in adjacent terrains with different material properties. Thus, for example, if an icy satellite had some regions with high heat flow, these might yield more fluid slurries during impact. Rapid readjustment then could produce final craters with lower depth-to-diameter ratios than those in colder areas of higher viscosity. Similar ambiguities could arise from impactors of different velocities or sizes hitting identical surfaces.

Recent cooling models for the Galilean satellites suggest that subcrustal water may have persisted until relatively late in the histories of Ganymede and Callisto and may still be present below the surface of Europa [Squyres et al., 1983]. The surfaces of these icy bodies could respond to an impact event like viscous slurries with varying degrees of strength depending upon the relative proportions of solid and liquid in the affected target area.
Viscous effects could cause these craters to be smaller and deeper than those in planets lacking a liquid substrate.

Viscosity of the planetary surface is not the only material property determining the relevant scaling law. It has been calculated that the influence of target strength begins for craters smaller than about $1-\mathrm{km}$ diameter [ Gault, 1973] and dominates over gravity for diameters less than about $10 \mathrm{~m}$. Craters also begin to exhibit morphologic changes from bowl shapes to flat floors at diameters of about $1 \mathrm{~km}$ (under conditions of $1 \mathrm{~g}$ ) [Holsapple and Schmidt, 1980]. The coefficient of internal friction also

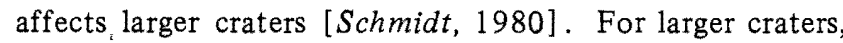
scaling is either of the gravity or viscous type, which differ primarily in the exponent which relates crater volume to projectile properties. However, oscillation of the transient crater bowl depends on the volume of the crater and the viscosity of the target. Hence the dynamic evolution of a crater and its final morphology are also controlled in large part by the type of scaling in effect. Relative age determinations of different surfaces on the icy satellites must take into account the possibility that craters subjected to viscous scaling laws would have different shapes and volumes than those controlled solely by gravity.

\section{SUMMARY}

Experimental impact craters formed in Newtonian fluids having a range of viscosities of $10^{-3} \mathrm{~Pa} \grave{\mathrm{s}}$ (water) to $60 \mathrm{~Pa} \mathrm{~s}$ (silicon oil) demonstrate a dependence of crater volume and shape (depth-to-diameter ratio) on viscosity.

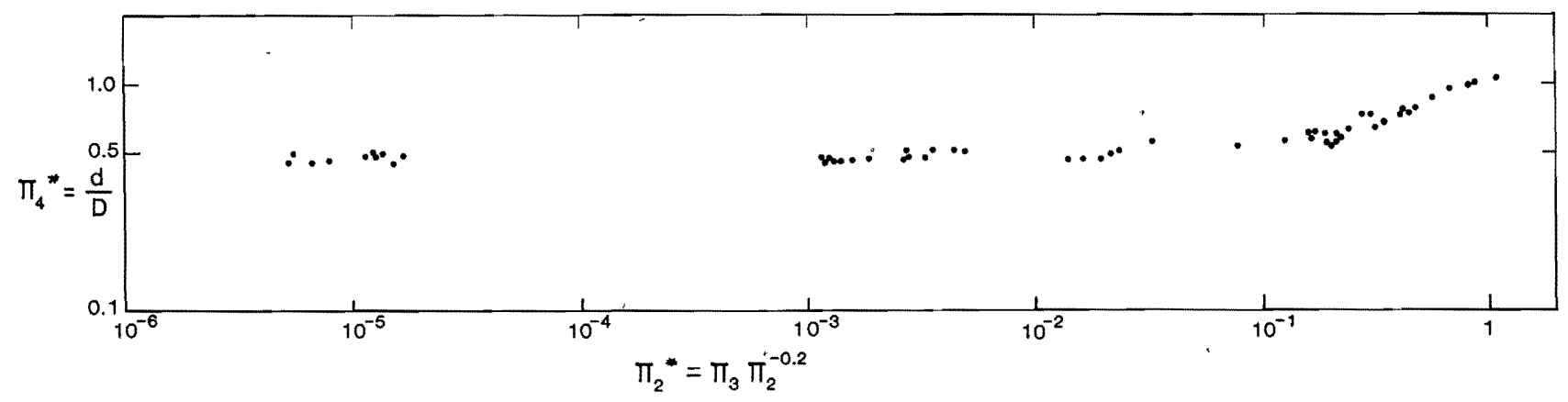

Fig. 3. Log-log plot of depth-to-diameter ratio for transient crater bowl $\left(\pi_{4}{ }^{*}\right)$ versus viscosity-gravity group $\left(\pi_{2}^{*}\right)$. 
The effect of viscosity dominates over gravity for impact events in which the following inequality holds: $\eta / \rho D_{p^{1.2}} u^{0.6} g^{0.2}>1.0$, where $\eta$ is the viscosity and $\rho$ is the density of the target, $D_{p}$ is the diameter and $u$ is the velocity of the projectile, and $g$ is the gravity. Viscous scaling leads to smaller, deeper craters than those controlled solely by gravity scaling. Conditions favoring viscous scaling are found on the outer planet icy satellites and may require modification of the usual tools for planetary surface age dating based on crater statistics.

\section{NOTATION}

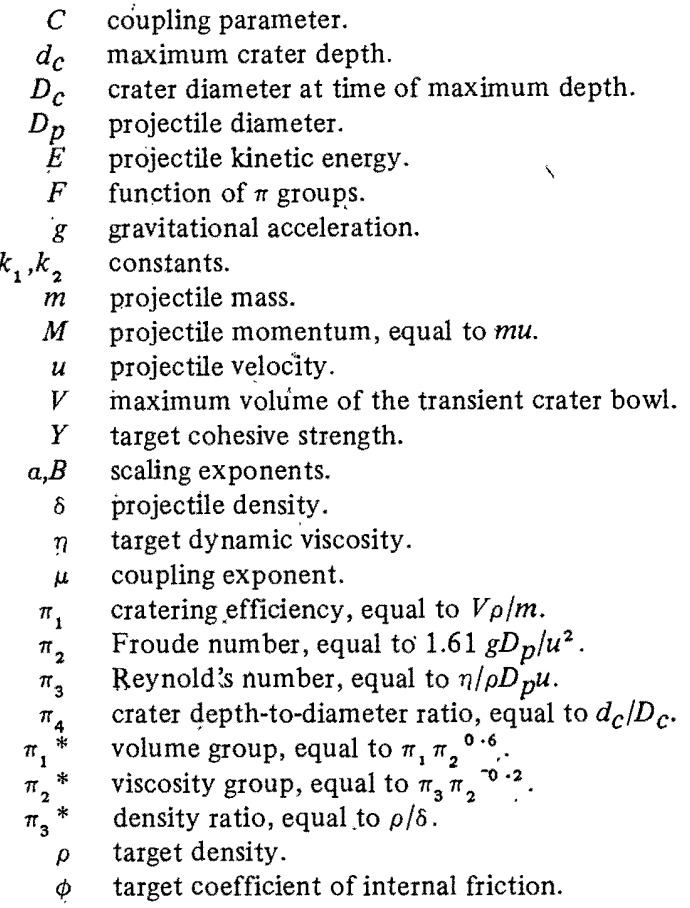

Acknowledgments. We thank reviewers. P. H. Schultz and W. B. McKinnon for their valuable suggestions. Keith Holsapple assisted in the dimensional analysis of our experimental data. K. Holsapple, R. M. Schmidt, and S. Croft provided many other useful comments. The authors thank the gun crew at the NASA Ames Vertical Gun Range for their cheerful assistance. Research supported by NASA grants NAGW-132, Jupiter Data Analysis Program (Planetary Geology), "and NAGW-56 (Planetary Geophysics), NASA Headquarters, Washington, D; C.

\section{REFERENCES}

Carr, M. H., L. S. Crumpler, J. A. Cutts, R. Greeley, J. E. Guest, and H. Masursky, Martian impact craters and emplacement of ejecta by surface flow, J. Geophys. Res., 82, 4055-4065, 1977.

Dow Corning Company, Information About Silicone Fluids, Midland, MI., 1966.

Fink, J. H., R. Greeley, and D. E. Gault, Impact cratering experiments in Bingham materials and the morphology of craters on Mars and Ganymede, Proc. Lunar Planet. Sci. Conf., 12th, 1649-1666, 1981.

Gault, D. E., Displaced mass, depth, diameter and effects of oblique trajectory for impact craters formed in dense crystalline rocks, Moon, 6, 32-44, 1973.

Gault, D. E., and R. Greeley, Exploratory experiments of impact craters formed in viscous-liquid targets: Analogs for Martian rampart craters?, Icarus, 34, 486-495, 1978.

Gault, D. E., and C. P. Sonett, Laboratory simulation of pelagic asteroidal impact: Atmospheric injection, benthic topography, and the. surface wave radiation field, in Geological Implications of Impacts of Large Asteroids and Comets on the Earth, edited by L. T. Silver and P. H. Schultz, Spec. Pap. Geol. Soc. Am., 190, pp. 69-92, 1982.

Gault, D. E., and J. A. Wedekind, Experimental hypervelocity impact into quartz sand, II, Effects of gravitational acceleration, in Impact and Explosion Cratering, edited by D. J. Roddy, R. O. Pepin, and R. B. Merrill, pp. 1231-1244, Pergamon, New York, 1977.

Gault, D. E., and J. A. Wedekind, Experimental impact 'craters' formed in water: Gravity scaling realized (abstract), Eos Trans. $A G U, 59,1121,1978$.

Greeley, R., J. H. Fink, D. E. Gault, D. B. Snyder, J. E. Guest, and P. H. Schultz, Impact cratering in viscous targets: Experimental results, Proc. Lunar Planet. Sci. Conf., 11 th, 2075-2097; 1980.

Greeley, R., J. H. Fink, D. E. Gault, and J. E. Guest, Impact cratering in simulated icy satellites, in The Satellites of Jupiter, edited by D. M. Morrison, pp. 340-378, University of Arizona Press, Tucson, 1982.

Holsapple, K. A., A comparison of scaling laws for planetary impact cratering: Experiments, calculations and theory (abstract), Lunar Planet. Sci. Conf., 12, 331-332, 1982.

Holsapple, K. A., and R. M. Schmidt, On the scaling of crater dimensions, 1, Explosive processes, J. Geophys. Res., 85, 72477256,1980 .

Holsapple, K. A., and R. M. Schmidt, On the scaling of crater dimensions, 2, Impact processes, $J$. Geophys. Res., 87, 18491870,1982 .

Horner, V. M., and R. Greeley, Pedestal craters on. Ganymede, Icarus, 51, 549-562, 1982.

Melosh, H. J., A schematic model of crater modification by gravity, J. Geophys. Res., 87, 371-380, 1982.

Passey, Q. R., and E. M. Shoemaker, Craters and basins on Gany: mede and Callisto: Morphological indicators of crustal evolution, in The Satellites of Jupiter, edited by D. M. Morrison, pp. 379434, University of Arizona Press, Tucson, 1982.

Pierson, T. C., Erosion and deposition by debris flows at $\mathrm{Mt}_{\text {e }}$ Thomas, North Canterbury, New Zealand, Earth Surf. Processes, $5,227-247,1980$.

Schmidt, R. M., Meteor Crater: Energy of formation-Implications of centrifuge scaling, Proc. Lunar Planet. Sci. Conf., 11th, 2099-2128, 1980.

Schultz, P. H., and D. E. Gault, Atmospheric effects on Martian ejecta emplacement, J. Geophys. Res., 84, 7669-7687, 1979.

Smith, B. A., and the Voyager Imaging Team, Encounter with Saturn: Voyager 1 Imaging Science results, Science, 212, 163$190,1981$.

Squyres, S. W., R. T. Reynolds, P. M. Cassen, and S. J. Peale, Liquid water and active resurfacing on Europa, Icarus, in press, 1983.

Strom, R. G., and A. Woronow, Origins of impacting objects in the solar system: The evidence from Saturn (abstract), in Saturn Conference, Tucson, p. 98, University of Arizona Press, Tucson, 1982.

J. Fink and R. Greeley, Department of Geology, Arizona State Univềrsity, Tempe, $\mathrm{AZZ} 85287$.

D. Gault, Murphys Center for Planetology, Box 833, Murphys, CA 95247

(Received August 29, 1983;

revised September 22, 1983;

accepted September 23, 1983.) 